Maurizio Cecconi Andrew Rhodes

\section{Erratum to: Pulse pressure: more than 100 years of changes in stroke volume}

Published online: 7 May 2011

(C) Copyright jointly held by Springer and ESICM 2011

The online version of the original article can be found under doi:10.1007/s00134-011-2155-y.

\section{Cecconi $(\bowtie) \cdot$ A. Rhodes}

Department of Intensive Care Medicine,

St George's Healthcare NHS Trust and St George's

University of London, London SW17 0QT, UK

e-mail: mauriziocecconi@hotmail.com

Tel.: +44-208-7250879

Fax: +44-208-7250879

\section{Erratum to: Intensive Care Med}

\section{DOI 10.1007/s00134-011-2155-y}

Two errors occurred in the penultimate paragraph of this editorial. The published and corrected versions of the passages concerned are given below, with the corrections underlined:

\section{Incorrect:}

Dufour et al. [22], in their paper in this issue, take the concept one step further forward. They demonstrated that PLR can be performed in a completely non-invasive way using vascular tonometry.

Correct:

Dufour et al. [22], in their paper in this issue, take the concept one step further forward. They demonstrated that changes in SV can be tracked in a completely non-invasive way using vascular tonometry.

Incorrect:

SphygmoCor is as good as an invasive measurement at the femoral site as a predictor of fluid responsiveness during a PLR test.

Correct:

SphygmoCor is as good as an invasive measurement at the femoral site to monitor changes in SV during a fluid challenge. 